\title{
Synthesis and Characterization of Aluminium Base in situ Metal Matrix Composites by Spark Plasma Sintering
}

\author{
B. Mallik ${ }^{1}$, K. Sikdar ${ }^{1}, \&$ D. Roy ${ }^{1}$ \\ ${ }^{1}$ Materials \& Metallurgical Engineering Department, National Institute of Foundry and Forge Technology, Hatia, \\ Ranchi-834003, India \\ Correspondence: D. Roy, Materials \& Metallurgical Engineering Department, National Institute of Foundry and \\ Forge Technology, Hatia, Ranchi-834003, India. E-mail: droy2k6@gmail.com
}

Received: November 12, 2017

Accepted: November 29, 2017 Online Published: December 29, 2017

doi:10.5539/jmsr.v7n1p14

URL: https://doi.org/10.5539/jmsr.v7n1p14

\begin{abstract}
Fe-aluminide and alumina reinforced in-situ aluminium based metal matrix composite was prepared by spark plasma sintering (SPS) of aluminium and nanosized $\mathrm{Fe}_{2} \mathrm{O}_{3}$ powder mixture. In-situ reinforcements were formed during SPS by exothermal reaction between aluminium and nano-size $\mathrm{Fe}_{2} \mathrm{O}_{3}$ particle. The thermal characteristics of the in-situ reaction were studied by differential scanning calorimetry (DSC). Field Emission Scanning Electron Microscopy (FESEM) along with the Energy Dispersive Spectroscopy (EDS) and X-ray diffraction (XRD) techniques were used to study the microstructural architecture of the composites as a function of SPS temperature and the volume fraction of reinforcement. Microhardness measurement of the composite shows significant increase in hardness with increase in SPS temperature and volume fraction of secondary phase.
\end{abstract}

Keywords: In-situ, Fe-aluminide, metal-matrix-composite, nanosize, Spark plasma Sintering

\section{Introduction}

During the last two decades, metal matrix composites (MMC) have emerged as an important class of materials for structural, wear, thermal, transportation and electrical applications. These composites possess superior strength to weight and high strength to cost ratio, when compared with their equivalent commercial alloys (Tjong \& Ma, 2000). It has been reported that the properties of the MMCs are influenced to a great extent by the nature of the reinforcements and their distribution in the host metal matrix (Tjong \& Ma, 2000; Everett, \& Arsenault, 1991; Ibrahim, Mohamed, \& Lavernia, 1991). Traditionally, these composites were prepared by powder metallurgy and diverse melting and casting routes (Chawla, 2012; El Baradie, 1990). However, in all these cases the scale of reinforcing phases and their distribution is constrained by the starting size of the reinforcements (Sheibani \& Najafabadi, 2007; Gotman, Koczak, \& Shtessel, 1994).

Recently, the technique of reinforcing metal matrices by in-situ reaction has gained considerable attention (Kuruvilla, Prasad, Bhanuprasad, \& Mahajan, 1990; Laksmi, Lu, \& Gupta, 1998). In this technique, the reinforcing phase(s) is (are) formed in the host matrix via in-situ chemical reaction between the matrix and the precursor element(s)/compound(s) during the composite fabrication. These composites, termed as in-situ metal matrix composites and often referred as second generation metal matrix composites (Gu, \& Shen, 2007; Song et al., 2008; Li et al., 2003; Tong, 1998), offer many advantages over the conventional composites. The most important advantage among many is that the reinforcements so formed by the in-situ reaction are finer in size and their distribution is more uniform, resulting in better mechanical properties of composites. However, here it would be worthwhile to mention that in most of the cases due to the high initiation temperature of the in-situ reaction(s), formation of the reinforcements within the host matrix necessitates high processing temperature. But processing the composites at high temperatures involves the risk of oxidation of the matrix and may also cause agglomeration and coarsening of the reinforcements, which will cast an adverse influence on the mechanical properties of the composite.

In the above perspective, it is to be noted that nano dimensional particles possess better chemical reactivity as compared to their coarser counterparts (Shen, Zou, Jin, \& Jiang, 2007). Therefore, it is expected that the use of nanosized precursors in the processing of the in-situ composites will decrease the onset temperature and thereby would improve the kinetics of the in-situ reaction(s). Moreover, occurrence of such reactions at lower temperature reduces the chance of oxidation, agglomeration and coarsening of the reinforcements. 
In recent years, the spark plasma sintering (SPS) process has been developed to obtain dense, near-net shaped bulk products from nanometer-size powders. During SPS, densification proceeds by applying high direct, pulsed current at low potential through the powder compact with externally applied pressure (Omori, 2000; Xü, Jia, \& Cao, 2005; Nygren \& Shen, 2003). In the process, the powder compact is subjected to cycles of very rapid heating and cooling with very short holding time at a sintering temperature, lower than that in normal hot pressing (Nygren \& Shen, 2003). Recently, mechanical alloying followed by SPS has been used to fabricate $\mathrm{Al}_{3} \mathrm{Ti}$ (Nygren \& Shen, 2003) and $\mathrm{Al}_{3} \mathrm{Zr}$ (Lee, Moon, \& Lee, 2006; Moon, Kim, \& Lee, 2002; Lee et al., 2003) based nanocrystalline, intermetallic alloys with attractive mechanical properties.

The present investigation aims at developing a mechanically stiffer and stronger in-situ Al matrix composite containing finely dispersed $\mathrm{Al}_{2} \mathrm{O}_{3}$ and $\mathrm{Fe}$-aluminide reinforcements by spark plasma sintering of $\mathrm{Al}$ powder and nanosized $\mathrm{Fe}_{2} \mathrm{O}_{3}$ powder.

\section{Experimental Procedures}

\subsection{Composites Fabrication}

Aluminium powder of $99 \%$ purity with an average particle size $\sim 20 \mu \mathrm{m}$ (Loba Chemie Pvt Ltd, Mumbai) and nanosized $\mathrm{Fe}_{2} \mathrm{O}_{3}$ powder (average particle size $\sim 5.6 \mathrm{~nm}$ ) prepared by dry milling were used for preparing $\left(\mathrm{Al}+\mathrm{Fe}_{2} \mathrm{O}_{3}\right)$ green powder mix. The powders were weighed separately and mixed in a small plastic jar containing 10 number of $4 \mathrm{~mm}$ steel balls. The weight of aluminium and nanosized $\mathrm{Fe}_{2} \mathrm{O}_{3}$ powders was adjusted in such a way so that the composite formed by the complete in-situ reaction will contain the desired volume percent reinforcements as shown in Table 1.

Table 1. Composite sample identity with the expected vol. \% of the reinforcing phase

\begin{tabular}{cc}
\hline Sample designation & Volume \% of reinforcement \\
\hline $\mathrm{AF}_{1}$ & 10 \\
$\mathrm{AF}_{2}$ & 20 \\
$\mathrm{AF}_{3}$ & 30 \\
$\mathrm{AF}_{4}$ & 40 \\
$\mathrm{AF}_{5}$ & 50 \\
\hline
\end{tabular}

The powder mix, so prepared were put into a graphite die (outside and inside diameters are 30 and $15 \mathrm{~mm}$ respectively) and consolidated by spark plasma sintering (Sumitomo Coal Mining, Japan). SPS was carried out into vacuum, at 700,800 and $900{ }^{\circ} \mathrm{C}$ under $50 \mathrm{MPa}$ uniaxial pressure and 10 minute holding time. The rate of heating was maintained at $50 \mathrm{~K} / \mathrm{min}$. The SPSed pellets were cylindrical $15 \mathrm{~mm}$ diameter and $5 \mathrm{~mm}$ thickness. To avoid any carbon contamination from graphite die, SPSed pellets were grounded by abrasive paper.

\subsection{Characterization}

The thermal characteristics of the in-situ reaction in the green compacts, expected to yield 100 vol. $\%\left(\mathrm{Al}_{2} \mathrm{O}_{3}+\mathrm{Fe}-\right.$ aluminide) reinforcement on complete reaction, were studied under argon gas atmosphere with the aid of a differential scanning calorimeter (DSC, Mettler, TA400). The flow rate of argon gas was maintained at $80 \mathrm{cc} / \mathrm{min}$ throughout the experiment. The green compacts were heated from room temperature to $700^{\circ} \mathrm{C}$ at a predetermined heating rate of $10^{\circ} \mathrm{C} / \mathrm{min}$ and then cooled to room temperature at a cooling rate of $10^{\circ} \mathrm{C} / \mathrm{min}$. In addition to the above studies, DSC investigation under identical environmental condition was also performed on the ball milled powder sample of $\mathrm{Fe}_{2} \mathrm{O}_{3}$ so that the results can be used as a reference to interpret the thermal characteristics of the compact during heating and cooling.

XRD studies on the SPS composite samples were carried out using $\mathrm{Cu}-\mathrm{K}_{\alpha}$ radiation. Prior to the analyses, the XRD patterns were corrected for the effects of the $\mathrm{K}_{\alpha 2}$ radiation. The particle size of the ball milled $\mathrm{Fe}_{2} \mathrm{O}_{3}$ powders were evaluated from the XRD patterns by taking recourse to the single line profile analysis technique (Klug \& Alexander, 1974).

A Field emission gun assisted scanning electron microscope (FESEM, Carl Zeiss, Supra 40) along with the energy dispersion spectroscopy (EDS) was used to study the microstructural architecture and composition of the different phases of the composite samples.

Average values of hardness on different phases of the composite samples were measured with the help of a standard Vickers hardness tester (Type 3212, Zwick, Ulm Germany) using a load of 50gm applied for 15s. The average hardness values were determined from 10 identical measurements. 


\section{Results and Discussion}

\subsection{Characteristics of in-situ Reaction}

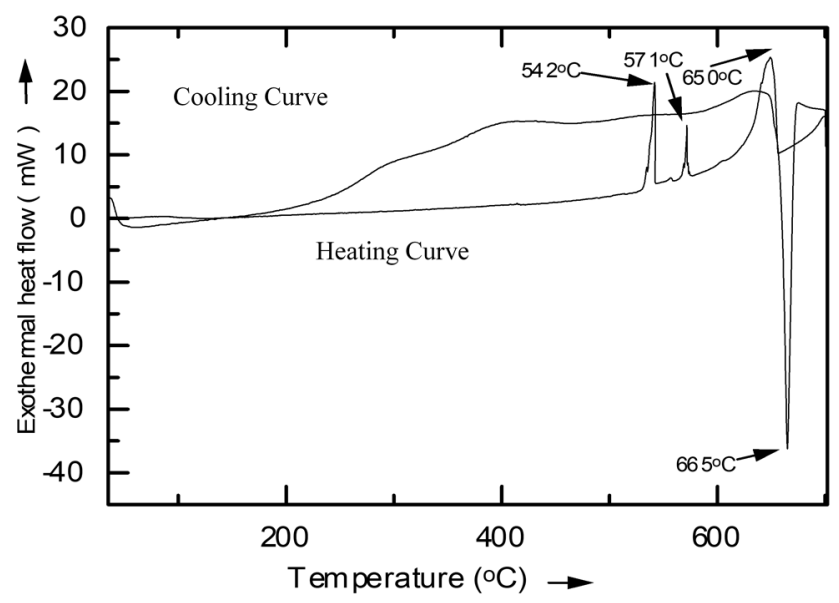

Figure 1. DSC heating and cooling plot of the green compact expected to yield $100 \mathrm{vol} \%\left(\mathrm{Al}_{2} \mathrm{O}_{3}+\mathrm{Fe}\right.$-aluminide $)$ reinforcement on complete reaction

Figure 1 presents the DSC results obtained with the green compact during the heating and cooling cycle without any isothermal holding at $700^{\circ} \mathrm{C}$. The exothermic peak observed at $650^{\circ} \mathrm{C}$ in the cooling curve is attributed to the heat released during solidification of the unreacted aluminum. Here, it can be clearly seen that the total amount of heat evolved during solidification is much less compared to the heat absorbed during melting of aluminum. This suggests that the in-situ reaction between nanometric iron oxide particles and molten aluminum is more favorable than the solid-state reaction due to better and intimate contact of $\mathrm{Fe}_{2} \mathrm{O}_{3}$ particles with molten Al. The exothermic peak observed in the cooling curve at $571{ }^{\circ} \mathrm{C}$ may be assigned to either magnetic ordering or $\left(\alpha+\beta_{2}\right)$ transformation of $\mathrm{Fe}_{3} \mathrm{Al}$. Similarly, the peak at $542^{\circ} \mathrm{C}$ can be ascribed either to $\alpha+\mathrm{DO}_{3}$ or entirely $\mathrm{DO}_{3}$ transformation of $\mathrm{Fe}_{3} \mathrm{Al}$. Therefore, we conclude that the in-situ reaction between nanosize $\mathrm{Fe}_{2} \mathrm{O}_{3}$ and $\mathrm{Al}$ will lead to the evolution of Fealuminide particles in the $\mathrm{Al}$ matrix. However, it is to be noted that the evolution of intermetallic particulate reinforcement and their type would depend on the temperature and amount of aluminum and nanosized $\mathrm{Fe}_{2} \mathrm{O}_{3}$ powder.

\subsection{Microstructure and Properties}

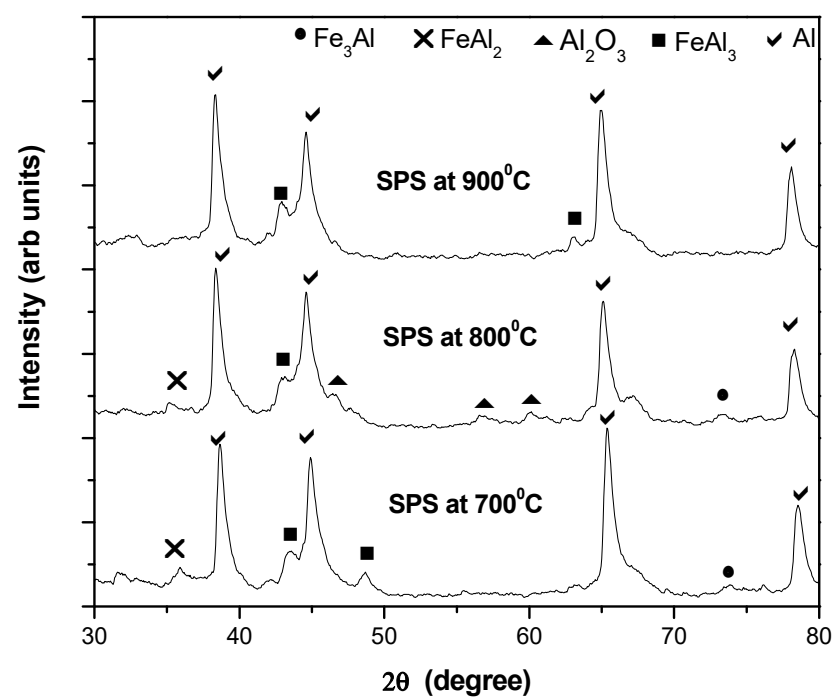

Figure 2. XRD patterns of 10 vol. $\%\left(\mathrm{Al}_{2} \mathrm{O}_{3}+\mathrm{Fe}\right.$-aluminide) reinforced $\mathrm{Al}$ matrix composite prepared by $\mathrm{SPS}$ at different temperature 


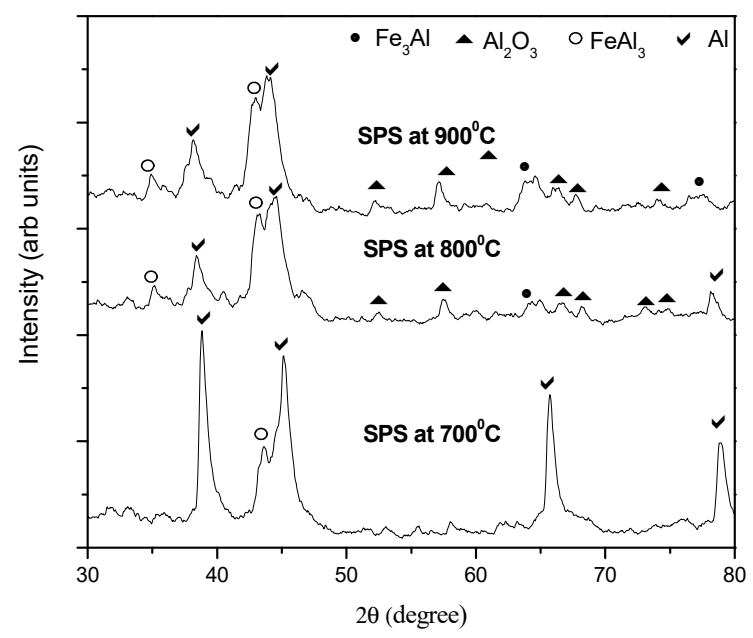

Figure $3 \mathrm{XRD}$ patterns of $30 \mathrm{vol} . \%\left(\mathrm{Al}_{2} \mathrm{O}_{3}+\mathrm{Fe}\right.$-aluminide) reinforced $\mathrm{Al}$ matrix composite prepared by SPS at different temperature

The type of reinforcements formed in the composite samples with respect to the hot pressing temperature and composition were investigated using the XRD technique and the representative patterns are shown in Fig 2 and 3. XRD pattern analysis reveals the presence of $\mathrm{FeAl}_{2}, \mathrm{FeAl}_{3}, \mathrm{Fe}_{3} \mathrm{Al}, \mathrm{Al}_{2} \mathrm{O}_{3}$ and unreacted $\mathrm{Al}$ in the composite samples. The presence of the above mentioned Fe-aluminides and $\mathrm{Al}_{2} \mathrm{O}_{3}$ in the composite samples confirms the occurrence of the following in-situ reactions during SPS.

$$
\begin{aligned}
& \mathrm{Fe}_{2} \mathrm{O}_{3}+2 \mathrm{Al}=\mathrm{Al}_{2} \mathrm{O}_{3}+2 \mathrm{Fe} \\
& \mathrm{xFe}+\mathrm{yAl}=\mathrm{Fe}_{\mathrm{x}} \mathrm{Al}_{\mathrm{y}} \quad(\mathrm{x}, \mathrm{y} \text { can be } 1,2 \text { or } 3)
\end{aligned}
$$

Here, it is to be noted that the initiation temperature of the above reactions with the conventional micron sized $\mathrm{Fe}_{2} \mathrm{O}_{3}$ powder is much higher compared to the hot pressing temperatures of this investigation under consideration. Therefore, we conclude that the onset temperature of the in-situ reactions has decreased significantly with the use of nanosized $\mathrm{Fe}_{2} \mathrm{O}_{3}$ powder.
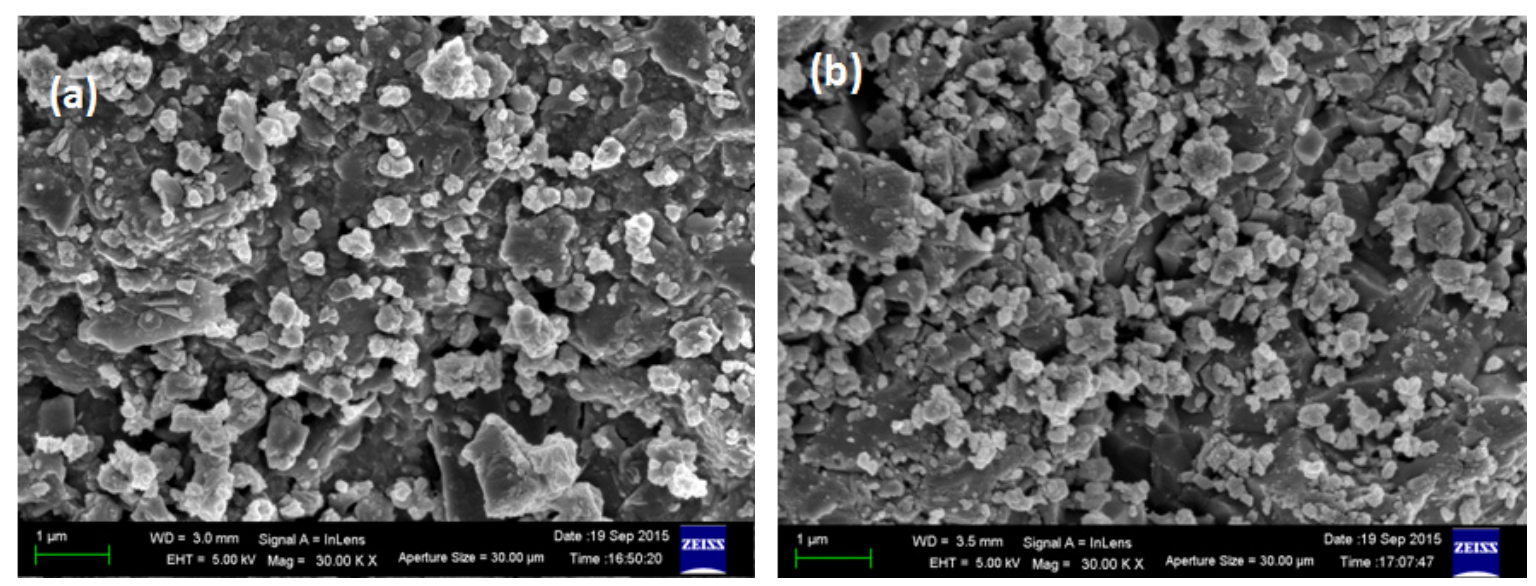

Figure 4. FESEM micrographs of (a) 10 vol. $\%$ and (b) 30 vol. $\%$ reinforced composite prepared by SPS at $900^{\circ} \mathrm{C}$

Representative FESEM micrographs of the in situ composite with varying reinforcement content prepared by SPS at $900^{\circ} \mathrm{C}$ are illustrated in Figs. 4 a-b. The microstructural feature of the composites reveals the presence of very fine (less than $1 \mu \mathrm{m}$ ) and well distributed reinforcements (bright contrast) in the host aluminum matrix. EDS investigations and analysis reveal existence of Fe-aluminide and $\mathrm{Al}_{2} \mathrm{O}_{3}$ in the bright areas and aluminium in the dark areas. The size of the particulate reinforcements in the host matrix has been found to increase with the increase in reinforcement content. This has been attributed to the clustering and agglomeration effects during processing. 


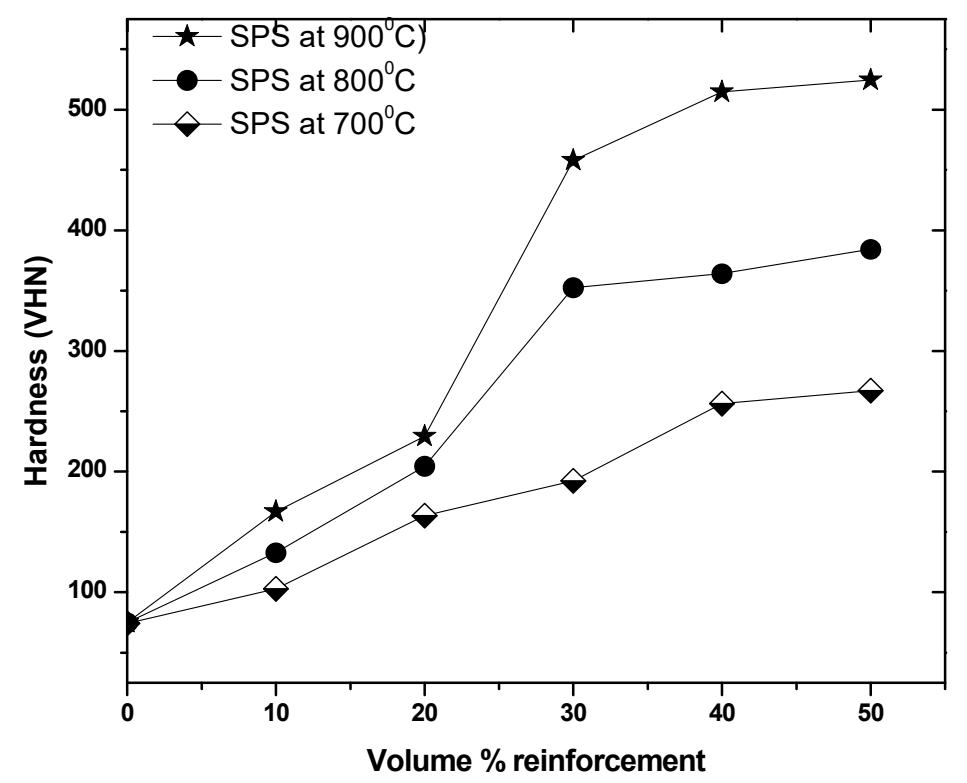

Figure 5. Hardness variation with respect to the vol. \% of reinforcement phase for the composite samples prepared by SPS at 700,800 and $900^{\circ} \mathrm{C}$

Variations in the Vickers hardness values recorded on the bright and dark shaded microstructural areas as a function of temperature and reinforcement content is shown in Figure 5. The standard deviation of the hardness values recorded on the bright and dark areas has been found to be \pm 10 and \pm 5 VHN respectively. It has been found that the hardness increase remarkably with the increase in temperature and reinforcement content. Considering the microstructural features of the composite samples, EDS results and hardness values, we infer that the formation of hard $\mathrm{Al}_{2} \mathrm{O}_{3}$ and intermetallic phases via the in- situ reaction became kinetically more favorable with the increase in processing temperature.

\section{Conclusions}

Based on the investigation the main results are summarized as follows:

a) Fe-alumide and $\mathrm{Al}_{2} \mathrm{O}_{3}$ dispersed in-situ Aluminium base metal matrix nano composites can be prepared by Spark plasma Sintering of the green compacts containing nanosized $\mathrm{Fe}_{2} \mathrm{O}_{3}$ powder and commercially available aluminium powder.

b) The reinforcements are formed by the in situ exothermal reaction between nano-sized $\mathrm{Fe}_{2} \mathrm{O}_{3}$ and aluminium and during sintering.

c) The beginning temperature of the in-situ reaction decreases considerably with the use of nano-sized $\mathrm{Fe}_{2} \mathrm{O}_{3}$ powder.

\section{References}

Chawla, K. K. (2012). Composite materials: science and engineering. Springer Science \& Business Media.

El Baradie, M. A. (1990). Manufacturing aspects of metal matrix composites. Journal of Materials Processing Technology, 24, 261-272.

Everett, R. K., \& Arsenault, R. J. (1991). Metal matrix composites: mechanisms and properties. Academic Press.

Gotman, I., Koczak, M. J., \& Shtessel, E. (1994). Fabrication of Al matrix in situ composites via self-propagating synthesis. Materials Science and Engineering: A, 187(2), 189-199.

Gu, D., \& Shen, Y. (2007). Influence of reinforcement weight fraction on microstructure and properties of submicron $\mathrm{WC}-\mathrm{Co} \mathrm{p} / \mathrm{Cu}$ bulk MMCs prepared by direct laser sintering. Journal of alloys and compounds, 431(1), 112-120.

Ibrahim, I. A., Mohamed, F. A., \& Lavernia, E. J. (1991). Particulate reinforced metal matrix composites-a review. Journal of materials science, 26(5), 1137-1156. 
Jang, H. S., Kang, C. W., Kim, Y., Hong, K. T., \& Kim, S. J. (2004). Effects of Mn addition on microstructure and mechanical properties of $(\mathrm{Al}+\mathrm{x}$ at. $\% \mathrm{Mn}) 3 \mathrm{Ti}$ intermetallic compounds prepared by mechanical alloying and spark plasma sintering. Intermetallics, 12(5), 477-485.

Klug, H. P., \& Alexander, L. E. (1974). X-ray diffraction procedures for polycrystalline and amorphous materials ( $2^{\text {nd }}$ ed., p. 643). New York: John Wiley \& Sons.

Kuruvilla, A. K., Prasad, K. S., Bhanuprasad, V. V., \& Mahajan, Y. R. (1990). Microstructure-property correlation in AlTiB2 (XD) composites. Scripta Metallurgica et Materialia, 24(5), 873-878.

Laksmi, S., Lu, L., \& Gupta, M. (1998). In situ preparation of TiB2 reinforced Al based composite. J Mater Process Technol, 73, 160-166.

Lee, S. H., Moon, K. I., \& Lee, K. S. (2006). Enhancement of the fracture toughness of bulk L1 2-based (Al+ 12.5 at.\% M) $3 \mathrm{Zr}(\mathrm{M}=\mathrm{Cu}, \mathrm{Mn})$ intermetallics synthesized by mechanical alloying. Intermetallics, 14(1), 1-8.

Lee, S. H., Moon, K. I., Hong, H. S., \& Lee, K. S. (2003). Microstructural and mechanical properties of nanocrystalline $(\mathrm{Al}+12.5$ at.\% $\mathrm{Cu}) 3 \mathrm{Zr}$ alloys synthesized by planetary ball milling and spark plasma sintering. Intermetallics, 11(10), 1039-1045.

Li, P., Kandalova, E. G., Nikitin, V. I., Makarenko, A. G., Luts, A. R., \& Yanfei, Z. (2003). Preparation of AlTiC composites by self-propagating high-temperature synthesis. Scripta materialia, 49(7), 699-703.

Moon, K. I., Kim, S. C., \& Lee, K. S. (2002). A study on the microstructure of D0 23 Al 3 Zr and L1 2 (Al+ 12.5 at.\% Cu) $3 \mathrm{Zr}$ intermetallic compounds synthesized by PBM and SPS. Intermetallics, 10(2), 185-194.

Nygren, M., \& Shen, Z. (2003). On the preparation of bio-, nano-and structural ceramics and composites by spark plasma sintering. Solid State Sciences, 5(1), 125-131.

Omori, M. (2000). Sintering, consolidation, reaction and crystal growth by the spark plasma system (SPS). Materials Science and Engineering: A, 287(2), 183-188.

Sheibani, S., \& Najafabadi, M. F. (2007). In situ fabrication of Al-TiC metal matrix composites by reactive slag process. Materials \& design, 28(8), 2373-2378.

Shen, P., Zou, B., Jin, S., \& Jiang, Q. (2007). Reaction mechanism in self-propagating high temperature synthesis of TiC-TiB 2/Al composites from an Al-Ti-B 4 C system. Materials Science and Engineering: A, 454, 300309.

Song, M. S., Zhang, M. X., Zhang, S. G., Huang, B., \& Li, J. G. (2008). In situ fabrication of TiC particulates locally reinforced aluminum matrix composites by self-propagating reaction during casting. Materials Science and Engineering: A, 473(1), 166-171.

Tjong, S. C., \& Ma, Z. Y. (2000). Microstructural and mechanical characteristics of in situ metal matrix composites. Materials Science and Engineering: R: Reports, 29(3), 49-113.

Tong, X. C. (1998). Fabrication of in situ TiC reinforced aluminum matrix composites Part I: Microstructural characterization. Journal of materials science, 33(22), 5365-5374.

Xü, C. Y., Jia, S. S., \& Cao, Z. Y. (2005). Synthesis of Al-Mn-Ce alloy by the spark plasma sintering. Materials characterization, 54(4), 394-398.

\section{Copyrights}

Copyright for this article is retained by the author(s), with first publication rights granted to the journal.

This is an open-access article distributed under the terms and conditions of the Creative Commons Attribution license (http://creativecommons.org/licenses/by/4.0/). 